\title{
COMUNICAÇÃO
}

\section{ARMAZENAMENTO DE MORANGO SOB ATMOSFERA MODIFICADA E REFRIGERAÇÃO}

\author{
Storage of strawberry under modified atmosphere and refrigeration \\ Heloísa Helena de Siqueira ${ }^{1}$, Brígida Monteiro Vilas Boas² ${ }^{2}$ José Daniel Silva ${ }^{3}$, \\ Elisângela Elena Nunes ${ }^{4}$, Luiz Carlos de Oliveira Lima ${ }^{5}$, Mercê Teodora Aguil Santana ${ }^{6}$
}

\begin{abstract}
RESUMO
Objetivou-se, neste trabalho, prolongar a vida pós-colheita de morangos, submetidos à atmosfera modificada ativa $\left(2 \% \mathrm{O}_{2}+\right.$ $10 \% \mathrm{CO}_{2}$ e $\left.5 \% \mathrm{O}_{2}+5 \% \mathrm{CO}_{2}\right)$ e armazenados sob refrigeração $\left(9 \pm 1^{\circ} \mathrm{C}\right.$ e $99 \%$ UR) por 10 dias. O experimento foi realizado no DCA/ Ufla, em Lavras, MG. Diante dos resultados obtidos neste trabalho, pôde-se concluir que os morangos não sofreram influência da atmosfera modificada em relação aos frutos- controle, quanto aos parâmetros avaliados.
\end{abstract}

Termos para indexação: Fragaria x ananassa Duch., pós-colheita, vida de prateleira.

\section{ABSTRACT}

The goal of this work was to draw out the shelf-life of strawberries, submitted to the active modified atmosphere $\left(2 \% \mathrm{O}_{2}+\right.$ $10 \% \mathrm{CO}_{2}$ and $\left.5 \% \mathrm{O}_{2}+5 \% \mathrm{CO}_{2}\right)$ and stored under refrigeration $\left(9 \pm 1^{\circ} \mathrm{C}\right.$ and $99 \%$ UR) by 10 days. The experiment was carried through in the DCA/Ufla, in Lavras, MG. With the results gotten in this work, it may be concluded that the strawberries did not suffer any influence of the modified atmosphere in relation to the controlled fruits, according to the evaluated parameters.

Index terms: Fragaria x ananassa Duch., postharvest, shelf life.

(Recebido em 4 de setembro de 2007 e aprovado em 10 de abril de 2008)

O morangueiro é uma planta herbácea e perene, pertencente à família das Rosáceas, gênero Fragaria. A parte comestível da planta é o morango, pseudofruto nãoclimatérico de aparência, aroma e sabor muito apreciados (PADOVANI, 1991).

Apesar das excelentes características sensoriais, o morango é um fruto altamente perecível, apresentando alta taxa respiratória e limitada vida pós-colheita e devido aos altos teores de umidade, açúcares e ácidos ele se torna um substrato ideal à proliferação de organismos patogênicos que causam consideráveis danos durante o transporte, amadurecimento, pós-colheita e armazenamento à temperatura ambiente.

A composição da atmosfera à qual os produtos são expostos na fase pós-colheita tem influência não só na taxa respiratória, como também na taxa metabólica geral deles. No armazenamento em atmosfera modificada, o ambiente é geralmente alterado pelo uso de filmes plásticos, permitindo que a concentração de dióxido de carbono $\left(\mathrm{CO}_{2}\right)$ proveniente do próprio produto aumente, e a concentração de oxigênio $\left(\mathrm{O}_{2}\right)$ diminua, à medida que ele é utilizado pelo processo respiratório. Nesse tipo de armazenamento, as concentrações de $\mathrm{O}_{2}$ e $\mathrm{CO}_{2}$ não são controladas, e variam com o tempo, temperatura, tipo de filme e com a taxa respiratória do produto (CHITARRA \& CHITARRA, 2005).

A modificação da atmosfera associada a baixas temperaturas de armazenamento, tem sido uma técnica promissora e de baixo custo para prolongar a vida útil de frutas e hortaliças, minimizando as perdas de qualidade e

\footnotetext{
'Engenheira Agrônoma, Doutora em Ciência dos Alimentos - Departamento de Ciência dos Alimentos/DCA - Universidade Federal de Lavras/UFLA Cx. P. 3037 - 37200-000 - Lavras, MG - heloisa.elias@yahoo.com.br

${ }^{2}$ Engenheira Agrônoma, Doutora em Ciência dos Alimentos - Escola Agrotécnica Federal de Machado - Rodovia Machado-Paraguaçu, Km 3 - 37750-000 - Machado, MG - bmvboas@hotmail.com

${ }^{3}$ Graduando em Engenharia de Alimentos - Perdigão Nova Mutum/GO - Rodovia Br 163, Km 587 - 120000-000 - Nova Mutum, GO jdalimentos@hotmail.com

${ }^{4}$ Farmacêutica-Bioquímica, Doutora em Ciência dos Alimentos - Fundação UNIRG Centro Universitário Gurupi/TO - Alameda Madrid, 545 - Jardim Sevilha - 77410-470 - Gurupi, TO

${ }^{5}$ Farmacêutico-Bioquímico, Doutor, Professor Adjunto - Departamento de Ciência dos Alimentos/DCA - Universidade Federal de Lavras/UFLA - Cx. P. 3037 -37200-000 - Lavras, MG - Icolima@ufla.br

${ }^{6}$ Farmacêutica-Bioquímica, Doutoranda em Ciência dos Alimentos - Departamento de Ciência dos Alimentos/DCA - Universidade Federal de Lavras/ UFLA - Cx. P. 3037 - 37200-000 - Lavras, MG - Icolima@ufla.br
} 
de peso, e a degradação por microrganismos. Objetivouse, neste trabalho, prolongar a vida pós-colheita de morangos, submetidos à atmosfera modificada ativa e armazenados sob refrigeração por 10 dias.

Foram utilizados morangos da cultivar Oso Grande adquiridos no comércio de Lavras/MG. Os frutos foram transportados para o Laboratório de Pós-colheita de Frutas e Hortaliças do Departamento de Ciência dos Alimentos da Universidade Federal de Lavras - Lavras/MG, onde foram selecionados de acordo com a uniformidade de cor, tamanho e ausência de injúrias mecânicas e fisiológicas. Em seguida, foram sanitizados com solução de hipoclorito de sódio $150 \mathrm{mg} \mathrm{L}^{-1}$ por 15 minutos, secos à temperatura ambiente, distribuídos aleatoriamente em bandejas de polipropileno seladas com filme de polietileno + polipropileno $60 \mathrm{~mm}$ de espessura utilizando-se Seladora de Bandejas - AP340 (TecMaq), Os tratamentos realizados foram: controle (atmosfera modificada passiva), atmosfera modificada ativa $2 \% \mathrm{O}_{2}$ e $10 \% \mathrm{CO}_{2}$ e atmosfera modificada ativa $5 \% \mathrm{O}_{2}$ e $5 \% \mathrm{CO}_{2}$, sendo todos armazenados sob refrigeração ( $9 \pm 1{ }^{\circ} \mathrm{C}$ e $99 \%$ UR), durante 10 dias.

As análises foram realizadas a cada 2 dias, sendo as seguintes: a) sólidos solúveis ( $\left.{ }^{\circ} \mathrm{Brix}\right)$, com auxílio de refratômetro digital ATAGO PR 100 (AOAC, 1992); b) acidez titulável (\% de acido cítrico), por titulometria de acordo com o Instituto Adolfo Lutz (2002); c) pH, com auxílio de pHmetro (AOAC, 1992); d) açúcares totais (\% de glicose por 100g de polpa), determinados por Somogy modificada por Nelson (1944); e) firmeza (N), utilizando Texturômetro Stable Micro System, modelo TAXT2i., probe $2 / \mathrm{N} ; \mathrm{f}$ ) pectina solúvel (mg de ácido galacturônico por $100 \mathrm{~g}$ de polpa), extraída segundo McCready \& McComb (1952) e os teores determinados colorimetricamente segundo Bitter \& Muir (1962); g) valores $\mathrm{L}^{*}$ e a*, utilizando colorímetro Minolta CR 300.

$\mathrm{O}$ experimento foi conduzido em delineamento inteiramente casualizado com 3 repetições, em esquema fatorial 3x6, sendo 3 níveis do fator atmosfera modificada (passiva, ativa $2 \% \mathrm{O}_{2}$ e $10 \% \mathrm{CO}_{2}$ e ativa $5 \% \mathrm{O}_{2}$ e $5 \% \mathrm{CO}_{2}$ ) e 6 níveis do fator tempo de armazenamento $(0,2,4,6,8$ e 10 dias). A parcela experimental foi constituída por 6 frutos. A análise estatística foi realizada com o auxilio do programa SISVAR (FERREIRA, 2000).

Não houve interação significativa entre os fatores atmosfera modificada e tempo de armazenamento para as variáveis sólidos solúveis (SS), acidez titulável (AT) e pH, sendo os valores médios de $7,75^{\circ}$ Brix, $1,09 \%$ ácido cítrico e 3,75, respectivamente, encontrados para morangos 'Oso Grande' mantidos sob refrigeração por 10 dias. Scalon et al. (1996), trabalhando na conservação de morangos cv. Sequóia em atmosfera modificada, durante 14 dias armazenados em câmara fria $\left(4^{\circ} \mathrm{C}\right.$ e $95 \%$ UR), encontraram valores médios de $\mathrm{SS}$, AT e $\mathrm{pH}$ de $8,03^{\circ} \mathrm{Brix}, 1,05 \%$ ácido cítrico e 3,54 respectivamente, nos frutos ensacados em filme de polietileno de alta densidade ( $15 \mathrm{~mm}$ de espessura). Tanada-Palmu \& Grosso (2005), estudando o efeito de embalagens na qualidade pós-colheita de morangos 'Oso Grande', armazenados sob refrigeração $\left(7-10^{\circ} \mathrm{C}\right.$ e $60-80 \%$ UR) por 16 dias, observaram decréscimo nos valores de AT e aumento nos teores de SS, para os frutos-controle e os acondicionados em bandejas envoltas com filme de policloreto de vinila ( $20 \mathrm{~mm}$ de espessura).

Houve interação significativa entre os fatores atmosfera modificada e tempo de armazenamento para a variável açúcares solúveis totais (Tabela 1). Apesar de ter ocorrido diferença estatística no zero, sexto e décimo dias de armazenamento, essa foi pouco expressiva uma vez que os valores oscilaram entre os tipos de atmosfera. O teor médio de açúcares solúveis totais dos morangos 'Oso Grande', acondicionados em atmosfera modificada foi de 4,90\%, estando próximo aos de Calegaro et al. (2002), que utilizaram atmosfera modificada na conservação pós-colheita de morangos 'Oso Grande', e encontraram valores médios de açúcares solúveis totais de 5,59\%, para frutos armazenados em temperatura ambiente por 14 dias. Já Scalon et al. (1996), obtiveram teor médio de $4,99 \%$, quando trabalharam com a conservação de morangos em atmosfera modificada.

Tabela 1 - Valores médios de açúcares solúveis totais (\% glicose) de morangos cultivar Oso Grande, armazenados sob atmosfera modificada e refrigeração $\left(9 \pm 1{ }^{\circ} \mathrm{C}\right.$ e $99 \%$ UR) durante 10 dias.

\begin{tabular}{ccccccc}
\hline & \multicolumn{7}{c}{ Tempo de armazenamento (dia) } \\
\cline { 2 - 7 } Atmosfera modificada & 0 & 2 & 4 & 6 & 8 & 10 \\
\hline Passiva & $6,20 \mathrm{a}$ & $4,94 \mathrm{a}$ & $5,74 \mathrm{a}$ & $4,88 \mathrm{~b}$ & $5,15 \mathrm{a}$ & $5,00 \mathrm{a}$ \\
Ativa $2 \% \mathrm{O}_{2}$ e $10 \% \mathrm{CO}_{2}$ & $5,13 \mathrm{~b}$ & $5,37 \mathrm{a}$ & $5,33 \mathrm{a}$ & $5,79 \mathrm{a}$ & $4,93 \mathrm{a}$ & $4,37 \mathrm{~b}$ \\
Ativa $5 \% \mathrm{O}_{2}$ e $5 \% \mathrm{CO}_{2}$ & $5,40 \mathrm{~b}$ & $5,05 \mathrm{a}$ & $5,50 \mathrm{a}$ & $5,36 \mathrm{ab}$ & $4,87 \mathrm{a}$ & $5,34 \mathrm{a}$ \\
\hline
\end{tabular}

Médias seguidas de mesma letra na coluna não diferem entre si, pelo teste de Tukey a $5 \%$. 
As variáveis firmeza e pectina solúvel foram afetadas pela interação significativa entre os fatores atmosfera modificada e tempo de armazenamento. A firmeza foi afetada significativamente apenas no oitavo dia de armazenamento (Tabela 2).

A textura é um atributo importante, porque além de definir a qualidade do fruto para o consumo 'in natura' e para o processamento, contribui para sua vida útil póscolheita (CONWAY et al., 1995), pois auxilia na resistência ao transporte e ao ataque de microrganismos. A diminuição da firmeza durante o amadurecimento tem sido atribuída a modificações e degradação dos componentes da parede celular (ANDREWS \& LI, 1994).

A variável pectina solúvel só não foi afetada significativamente no segundo e quarto dias de armazenamento (Tabela 2), sendo que no zero e oitavo dias os morangos acondicionados, em atmosfera passiva e ativa $5 \% \mathrm{O}_{2}$ e $5 \% \mathrm{CO}_{2}$ apresentaram os maiores valores. No sexto dia, a atmosfera ativa $5 \% \mathrm{O}_{2}$ e $5 \% \mathrm{CO}_{2}$ determinaram maiores teores de pectina solúvel, seguida da ativa $2 \% \mathrm{O}_{2}$ e $10 \% \mathrm{CO}_{2}$ e por último da passiva. Enquanto que no final do armazenamento, os morangos mantidos sob atmosfera modificada passiva apresentaram a maior solubilização péctica em relação às demais atmosferas modificadas.

Os valores $\mathrm{L}^{*}$ e $\mathrm{a}^{*}$ foram afetados significativamente apenas pelo fator atmosfera modificada (Tabela 3). Para a variável valor $\mathrm{L}^{*}$, os morangos armazenados sob atmosfera passiva apresentaram-se mais claros em relação aos acondicionados em atmosfera ativa $5 \% \mathrm{O}_{2}$ e $5 \% \mathrm{CO}_{2}$. Os frutos armazenados sob a atmosfera ativa $5 \% \mathrm{O}_{2}$ e $5 \% \mathrm{CO}_{2}$ apresentaram menor intensidade da cor vermelha em relação aos frutos armazenados nas demais atmosferas modificadas, para o valor $\mathrm{a}^{*}$.

Nunes et al. (1995), trabalhando com diferentes cultivares de morango armazenados por uma semana a 1 ${ }^{\circ} \mathrm{C}$ e posteriormente a 1 dia a $20^{\circ} \mathrm{C}$, encontraram valores médios de 34,58 e 32,23, para $\mathrm{L}^{*}$ e a*, respectivamente. No presente trabalho, obtiveram-se valores médios de $\mathrm{L}^{*}$ de 26,90 , sendo que esse valor foi inferior ao encontrado pelos autores citados acima, já o valor a* foi de 36,24 , estando próximo ao encontrado pelos mesmos.

Tabela 2 - Valores médios de firmeza (N) e pectina solúvel (mg ácido galacturônico.100g polpa) de morangos cultivar Oso Grande, armazenados sob atmosfera modificada e refrigeração $\left(9 \pm 1^{\circ} \mathrm{C}\right.$ e $99 \%$ UR) durante 10 dias.

\begin{tabular}{|c|c|c|c|c|c|c|}
\hline \multirow[b]{2}{*}{ Atmosfera modificada } & \multicolumn{6}{|c|}{ Tempo de armazenamento (dia) } \\
\hline & 0 & 2 & 4 & 6 & 8 & 10 \\
\hline & \multicolumn{6}{|c|}{ Firmeza } \\
\hline Passiva & $0,57 \mathrm{a}$ & $0,55 \mathrm{a}$ & $0,61 \mathrm{a}$ & $0,65 \mathrm{a}$ & $0,74 \mathrm{a}$ & $0,50 \mathrm{a}$ \\
\hline Ativa $2 \% \mathrm{O}_{2}$ e $10 \% \mathrm{CO}_{2}$ & $0,60 \mathrm{a}$ & $0,58 \mathrm{a}$ & $0,58 \mathrm{a}$ & $0,66 \mathrm{a}$ & $0,51 \mathrm{~b}$ & $0,55 \mathrm{a}$ \\
\hline \multirow[t]{2}{*}{ Ativa $5 \% \mathrm{O}_{2}$ e $5 \% \mathrm{CO}_{2}$} & $0,53 \mathrm{a}$ & $0,54 \mathrm{a}$ & $0,61 \mathrm{a}$ & $0,61 \mathrm{a}$ & $0,54 \mathrm{~b}$ & $0,48 \mathrm{a}$ \\
\hline & \multicolumn{6}{|c|}{ Pectina solúvel } \\
\hline Passiva & 85,27 a & 83,15 a & $76,00 \mathrm{a}$ & $99,26 \mathrm{c}$ & $156,16 \mathrm{a}$ & $192,05 \mathrm{a}$ \\
\hline Ativa $2 \% \mathrm{O}_{2}$ e $10 \% \mathrm{CO}_{2}$ & $64,01 \mathrm{~b}$ & $72,42 \mathrm{a}$ & $75,77 \mathrm{a}$ & $121,72 b$ & $110,77 \mathrm{~b}$ & $153,96 b$ \\
\hline Ativa $5 \% \mathrm{O}_{2}$ e $5 \% \mathrm{CO}_{2}$ & $91,81 \mathrm{a}$ & 76,93 a & $78,30 \mathrm{a}$ & $143,27 \mathrm{a}$ & $158,21 \mathrm{a}$ & $155,16 \mathrm{~b}$ \\
\hline
\end{tabular}

Médias seguidas de mesma letra na coluna não diferem entre si, pelo teste de Tukey a 5\%.

Tabela 3 - Valores L* e a* de morangos cultivar Oso Grande, armazenados sob atmosfera modificada e refrigeração (9 $\pm 1{ }^{\circ} \mathrm{C}$ e $99 \%$ UR) durante 10 dias.

\begin{tabular}{ccl}
\hline Atmosfera Modificada & Valor L* & Valor a* \\
\hline Passiva & $27,92 \mathrm{a}$ & $36,78 \mathrm{a}$ \\
Ativa $2 \% \mathrm{O}_{2}$ e $10 \% \mathrm{CO}_{2}$ & $26,77 \mathrm{ab}$ & $36,90 \mathrm{a}$ \\
Ativa $5 \% \mathrm{O}_{2}$ e $5 \% \mathrm{CO}_{2}$ & $26,0 \mathrm{~b}$ & $35,03 \mathrm{~b}$ \\
\hline
\end{tabular}

Médias seguidas de mesma letra na coluna não diferem entre si, pelo teste de Tukey a $5 \%$. 
Diante dos resultados obtidos neste trabalho, pôdese concluir que os morangos sofreram influência da atmosfera modificada em relação aos frutos-controle, quanto aos parâmetros açúcares totais, pectina solúvel e firmeza. Sendo que os demais não foram influenciados pela atmosfera modificada.

\section{REFERÊNCIAS BIBLIOGRÁFICAS}

ANDREWS, P. K.; LI, S. Parcial purification and characterizacion of b-galactosidase from sweet berry, a nonclimateric fruit. Journal Agricultural and Food Chemistry, Washington, v. 42, n. 10, p. 2177-2182, 1994.

\section{ASSOCIATION OF OFFICIAL ANALYTICAL} CHEMISTRY. Official methods of analysis of the Association of Official Analytical Chemistry. 12. ed. Washington, DC, 1992. 1015 p.

BITTER, T.; MUIR, H. M. A modified uronic acid carbazole reaction. Analytical Biochemistry, New York, v. 34, p. 330-334, 1962.

CALEGARO, J. M.; PEZZI, E.; BENDER, R. J. Utilização de atmosfera modificada na conservação de morangos em pós-colheita. Pesquisa Agropecuária Brasileira, Brasília, v. 37, n. 8, p. 1049-1055, ago. 2002.

CHITARRA, M. I. F.; CHITARRA, A. B. Pós-colheita de frutas e hortaliças: fisiologia e manuseio. 2. ed. Lavras: UFLA, 2005. $785 \mathrm{p}$.

CONWAY, W. S.; SAMS, C. E.; WATADA, A. E. Relationship between total and cell wall bound calcium in apples following postharvest pressure infiltration of calcium chloride. Acta Horticulturae, Wageningen, n. 398, p. 31-39, 1995.

FERREIRA, D. F. Análises estatísticas por meio do SISVAR para Windows versão 4.0. In: REUNIÃO
ANUAL DA REGIÃO BRASILEIRA DA SOCIEDADE

INTERNACIONAL DE BIOMETRIA, 45., 2000, São

Carlos, SP. Resumos... São Carlos: UFSCar, 2000. p. 235.

INSTITUTO ADOLFO LUTZ. Normas analíticas: métodos químicos e físicos para análise de alimentos. São Paulo, SP, 2002. v. 6, 371 p.

McCREADY, R. M.; McCOMB, E. A. Extraction and determination of total pectic materials in fruit. Analytical Chemistry, Washington, v. 24, n. 12, p. 1586-1588, Dec. 1952.

NELSON, N. A photometric adaptation of Somogy method for the determination of glucose. Journal of Biological Chemists, Baltimore, v. 153, n. 1, p. 375-384, 1944.

NUNES, M. C. N.; BRECHT, J. K.; MORAIS, A. M. M. B.; SARGENT, S. A. Physical and chemical quality characteristics of strawberries after storage are reduced by a short delay to cooling. Postharvest Biology and Technology, v. 6, p. 17-28, 1995.

PADOVANI, M. I. Morango: o delicado e o saboroso fruto da integração dos povos. São Paulo: Ícone, 1991. 68 p. (Coleção Brasil Agrícola).

SCALON, S. de P. Q.; CHITARRA, A. B.; CHITARRA, M. I. F.; ABREU, M. S. de. Conservação de morangos (Fragaria ananassa Duch) cv. Sequóia em atmosfera modificada. Revista Brasileira de Fruticultura, Cruz das Almas, v. 18, n. 3, p. 431-436, dez. 1996.

TANADA-PALMU, P. S.; GROSSO, C. R. F. Effect of edible wheat gluten-based films and coatings on refrigerated strawberry (Fragaria ananassa) quality. Postharvest Biology and Technology, 2005. 